\section{Determinantes econômicos da demanda por importações de produtos farmoquímicos e farmacêuticos}

\author{
Economic determinants of the demand for \\ importation of pharmacochemical and \\ pharmaceutical products
}

Determinantes económicos de la demanda de importaciones de productos farmoquímicos y farmacéuticos

\section{Resumo}

Este artigo analisa a relação entre a demanda por importações de produtos farmoquímicos e farmacêuticos e variáveis econômicas (taxa de câmbio, preço das importações e renda agregada), no Brasil, fazendo uso de dados mensais do período 1997-2014. Os principais resultados mostraram que aumentos na renda agregada e reduções nos preços das importações têm impacto positivo e significativo, respectivamente de forma elástica e inelástica, sobre as importações. A taxa de câmbio foi significativa apenas no modelo mais agregado. Portanto, a renda agregada se mostrou uma variável bastante robusta e com forte impacto sobre as importações dos produtos farmoquímicos e farmacêuticos. Considerando os argumentos explicitados na literatura de que o déficit no comércio internacional dessa indústria se relaciona com déficit em conhecimento e tecnologia, somando aos resultados encontrados neste trabalho, há indícios de que conforme o nível de atividade econômica cresce, ocorre maior demanda por esse tipo de produto, e, não havendo produção nacional suficiente, existe necessidade de importações, o que pode gerar pressões no déficit comercial desse segmento, representando dependência do Brasil a outros países.

Importação de Produtos; Comercialização de Medicamentos;

Preparações Farmacêuticas
Anderson Moreira Aristides dos Santos 1 César Augusto Oviedo Tejada 2

Paulo de Andrade Jacinto 3

doi: 10.1590/0102-311X00087916

\author{
Correspondência \\ A. M. A. Santos \\ Av. Presidente Getúlio Vargas 56, Maceió, AL 57046-140, \\ Brasil. \\ anderson_moreira_aristides@hotmail.com \\ 1 Curso de Mestrado em Economia Aplicada, Universidade \\ Federal de Alagoas, Maceió, Brasil. \\ 2 Programa de Pós-graduação em Organizações e Mercados, \\ Universidade Federal de Pelotas, Pelotas, Brasil. \\ 3 Programa de Pós-graduação em Desenvolvimento Econômico, \\ Pontifícia Universidade Católica do Rio Grande do Sul, Porto \\ Alegre, Brasil.
}




\section{Introdução}

A indústria farmacêutica faz parte do Complexo Econômico Industrial da Saúde (CEIS). Sua atividade está ligada à produção de medicamentos, fármacos, hemoderivados, vacinas, reagentes para diagnóstico, soros e toxinas 1 . Suas etapas produtivas possuem diferentes níveis de complexidade, desde atividades de pesquisa e desenvolvimento (P\&D) de fármacos até o marketing e comercialização dos produtos finais 2,3 .

Essa indústria é caracterizada por um oligopólio mundial diferenciado, com uma parte significativa de sua estrutura concentrada nas dez maiores empresas, porém sem existir uma com participação majoritária. Ademais, há um número expressivo de empresas de porte menor 1,4,5. As principais empresas líderes têm como sede os Estados Unidos e a Europa, apresentando um forte grau de internacionalização 1,4 . Nessa indústria, há barreiras à entrada associadas em grande parte às economias de escala oriundas de atividades P\&D e de marketing 1,4,6,7.

O Brasil está entre os dez maiores mercados farmacêuticos do mundo. As principais empresas são multinacionais com baixa taxa de inovação 5 , embora haja crescente participação de empresas nacionais, especialmente, devido às oportunidades de um mercado aberto, a partir de 1999, pelos medicamentos genéricos 1,5 .

O mercado farmacêutico no Brasil tem apresentado crescimento anual de $10 \%$ em seu faturamento, e a indústria do setor tem aumentado sua produção em $50 \%$ nos últimos anos 3,8. Contudo, essa indústria é altamente dependente das importações, sobretudo dos farmoquímicos, mas, crescentemente, também de bens finais como medicamentos 3,9. No ano de 2013, 25\% da oferta de medicamentos eram formadas por importados; a estatística para os farmoquímicos era de $74 \% 10$.

Gadelha 11 observa que o CEIS no Brasil depende das importações de produtos de maior conteúdo tecnológico e que têm como origem países do bloco Tratado Norte-Americano de Livre Comércio (North American Free Trade Agreement - NAFTA) e da União Europeia. Em contraste, as exportações brasileiras possuem como destino países em desenvolvimento.

Ampliando as discussões realizadas em Gadelha 11 e em Mota et al. 12, Mota 3 mostra que há indicações de especialização regressiva no Brasil, destacando o déficit de conhecimento e tecnologia que existe por trás do déficit comercial da indústria farmacêutica.

A literatura que analisa os determinantes econômicos da demanda por importações no Brasil é relativamente extensa 13,14,15,16,17,18,19,20,21, fazendo o uso de elasticidades e cobrindo os agregados totais ou mercados/segmentos específicos (bens intermediários, de capital, de consumo duráveis, de consumo não duráveis, agropecuários e lácteos). Os resultados indicam diferentes elasticidades, sugerindo um papel importante para renda, preço e taxa de câmbio como determinantes das importações. Entretanto, não há estudos que façam essas mensurações para as importações dos farmoquímicos e farmacêuticos.

Com essas considerações, o objetivo deste estudo é analisar a relação entre a demanda por importações de produtos farmoquímicos e farmacêuticos e as variáveis econômicas (taxa de câmbio, preço das importações e renda agregada) para o Brasil, por meio da estimação de elasticidades, com dados mensais do período 1997-2014. Tais informações poderão permitir melhor compreensão da trajetória crescente das importações desse segmento e de sua relação com as variáveis de interesse.

\section{Metodologia}

Uma função Cobb-Douglas foi utilizada para estimar as elasticidades constantes da demanda por importações de produtos farmoquímicos e farmacêuticos do Brasil. Em termos econométricos, a função é representada por um modelo log-log, onde os parâmetros estimados captam as elasticidades da demanda por essas importações em relação à taxa de câmbio, preço das importações e renda agregada. Por exemplo, a elasticidade-renda mensura a variação percentual na demanda por importações ocasionadas por um aumento de $1 \%$ na renda agregada.

Para obtenção dos dados de importações, este trabalho seguiu a Classificação Nacional de Atividades Econômicas (CNAE 2.0), observando o grupo de código 21. Ela possui correspondências com o sistema de classificação de estatísticas de comércio exterior do Brasil, tendo em conta os capítulos 30 e parte 
do 29 da Nomenclatura Comum do Mercosul (NCM), que passou a vigorar a partir do ano de 1997, em substituição à Nomenclatura Brasileira de Mercadorias (NBM). No entanto, não se tem compatibilidade significativa entre o NBM e NCM, motivo que determinou a escolha da periodicidade analisada no presente trabalho 3,12 .

As estimações foram realizadas com base em cinco variáveis dependentes: (i) farmoquímicos e farmacêuticos; (ii) farmoquímicos (insumo farmacêutico ativo - IFA); (iii) farmacêuticos; (iv) medicamentos; e (v) hemoderivados. A segunda e terceira são subitens da primeira, assim como a quarta e quinta são subitens da terceira variável (em que as importações dos farmacêuticos são formadas particularmente pelos medicamentos e hemoderivados).

O item i das importações tem como fonte o Ipeadata (http://www.ipeadata.gov.br), os demais foram obtidos diretamente do AliceWeb (http://aliceweb.mdic.gov.br/) do Ministério de Desenvolvimento, Indústria e Comércio (MDIC). Essas variáveis dependentes se referem ao quantum das importações; elas foram calculadas pela razão entre as importações em valores monetários (dólares) do respectivo item e o índice de preços das importações dos produtos farmoquímicos e farmacêuticos (obtidos do Ipeadata). Em outras palavras, devido à disponibilidade de dados, todos esses itens (i ao v) foram deflacionados pelo índice de preços agregados desse setor (farmoquímicos e farmacêuticos).

As séries preço das importações de bens desse setor, taxa de câmbio efetiva real e Produto Interno Bruto (PIB) em termos reais foram utilizadas como variáveis explicativas. As duas últimas têm como fonte o Sistema Gerenciador de Séries Temporais (SCS) do Banco Central do Brasil. E, ainda, uma variável binária correspondente à mudança de regime cambial (janeiro de 1999) foi incorporada como controle nas estimações.

Os dados deste trabalho têm periodicidade mensal, entre os anos 1997 e 2014 (dados anuais serão apresentados na análise de estatísticas descritivas). Números índices para as séries foram construídos, com base de janeiro de 1997 e, dessazonalizadas pelo programa X-13 ARIMA (US Census Bureau; https://www.census.gov/srd/www/x13as/). Todos os modelos incorporam os logaritmos naturais das variáveis (modelos $\log$ - $\log$ ).

A estimação de elasticidades via método dos mínimos quadrados ordinários poderia gerar conclusões errôneas, mostrando correlações espúrias. Além disso, por conta da possível simultaneidade entre os indicadores, viola-se a hipótese de ausência de correlação entre o termo de erro e o regressor. Dessa forma, este trabalho aplicou um modelo vetorial de correção de erro (VEC) 22,23.

Como pré-requisito, para se estimar um VEC, é necessário verificar se as séries possuem raiz unitária, ou seja, se elas são não estacionárias. Para tanto, dois testes foram aplicados: Dickey-Fuller aumentado (ADF) e Kwiatkowski, Phillips, Schmidt e Shin (KPSS).

O teste ADF apresenta a hipótese nula de que a série possui raiz unitária, logo, que ela é não estacionária, contra a hipótese alternativa de estacionaridade. Duas especificações foram testadas, com constante e com constante e tendência. Caso uma determinada série possua raiz unitária, aplica-se o teste para as primeiras diferenças das séries para analisar a ordem de integração. A extensão da defasagem foi obtida de acordo com critério de Schwarz.

Como o teste ADF sofre de baixo poder, ou seja, ele tende a falhar em rejeitar a hipótese nula de raiz unitária, mesmo quando ela deveria ser rejeitada, o teste KPSS pode complementar a análise de raiz unitária 22,24. O teste KPSS apresenta como hipótese nula estacionaridade da série, contra a hipótese alternativa de não estacionaridade.

As estimações do modelo VEC seguem as propostas de Johansen 25,26 e Johansen \& Juselius 27. Primeiramente, os modelos de vetor autorregressivo (VAR) devem ser utilizados para obtenção da defasagem ótima, tendo a sua escolha com base no critério de Schwarz. Em seguida, verificou-se a possibilidade de cointegração entre as séries, vale dizer, testar se elas possuem tendências estocásticas semelhantes. Em caso positivo, há evidência de uma relação de equilíbrio de longo prazo entre elas. Nessa abordagem, assume-se que as variáveis são determinadas endogenamente, e dois tipos de testes foram aplicados: o traço $\left(\lambda_{\text {traç }}\right)$ e o máximo autovalor $\left(\lambda_{\text {máx }}\right)$. Em geral, a hipótese nula inicia-se mais restritiva, isto é, com $\mathrm{r}=0$ vetores de cointegração. Quando os valores calculados de $\lambda_{\text {traço }}$ e $\lambda_{\text {máx }}$ são maiores do que os respectivos valores críticos, rejeita-se a hipótese nula.

Havendo vetores de cointegração, pode ser dito que há equilíbrio de longo prazo e as estimações das elasticidades podem ser obtidas pelo VEC. Outra informação que pode ser gerada refere-se à estimativa das elasticidades de curto prazo e um termo de ajuste para o equilíbrio de longo prazo, 
conhecido como mecanismo de correção de erros. Este trabalho focou nas relações de longo prazo. Para verificar a especificação do modelo foram aplicados testes de estabilidade do VEC, autocorrelação, heterocedasticidade e normalidade dos resíduos. Os cálculos deste trabalho foram realizados com o auxílio do software estatístico e econométrico Eviews 8 (http://www.eviews.com/home.html)

\section{Resultados}

A Tabela 1 apresenta a evolução das importações de produtos farmoquímicos e farmacêuticos e, para fins de comparação de suas exportações, com dados anuais, no período de 1997-2014. Constata-se que, no ano de 1997, as importações apresentavam um valor de US\$ 1,96 bilhão, e no ano de 2014 alcançaram o patamar de US\$ 8,94 bilhões, representando um crescimento nominal de 355\%.

Ocorreu aumento na razão entre os valores das exportações e importações. Apesar desse fato, o déficit comercial, diferença entre essas duas variáveis, aumentou durante o período de análise, alcançando US\$ 7,36 bilhões no ano de 2014. Nota-se, com base na coluna 6 dos dados, que o índice do volume das importações (quantum) cresceu 211\% entre 1997 e 2014, enquanto o volume das exportações cresceu $403 \%$.

Nota-se que a partir dos anos 2004-2005 aconteceu uma tendência de reduções na taxa de câmbio real (valorização cambial), de crescimento da renda agregada (mensurada pelo PIB), aumento nos preços das importações e aumento das importações dos produtos farmoquímicos e farmacêuticos (Figura 1).

$\mathrm{Na}$ Tabela 2, os índices do volume das importações de produtos farmoquímicos e farmacêuticos são apresentados considerando os itens mais desagregados. Como pode ser visto, houve um crescimento real de 94\% para os farmoquímicos e de 400\% para os farmacêuticos, entre os anos de 1997 e 2014. Levando em conta esse mesmo período, dentre os farmacêuticos, percebe-se, um crescimento de $238 \%$ para as importações de medicamentos e de $1.699 \%$ para os hemoderivados.

Tabela 1

Evolução das importações, exportações e saldo comercial dos farmoquímicos e farmacêuticos. Brasil, 1997-2014.

\begin{tabular}{lcccccc}
\hline Ano & $\begin{array}{c}\text { Exportações } \\
\text { (US\$ milhões) }\end{array}$ & $\begin{array}{c}\text { Importações } \\
\text { (US\$ milhões) }\end{array}$ & $\begin{array}{c}\text { Saldo } \\
\text { (US\$ milhões) }\end{array}$ & Razão & $\begin{array}{c}\text { Quantum das exportações } \\
\text { (índice = 100, em 1997) }\end{array}$ & $\begin{array}{c}\text { Quantum das importações } \\
\text { (índice = 100, em 1997) }\end{array}$ \\
\hline 1997 & 300,56 & $1.964,23$ & $-1.663,67$ & 15,30 & 100,00 & 100,00 \\
1998 & 333,08 & $2.187,84$ & $-1.854,76$ & 15,22 & 112,78 & 105,58 \\
1999 & 358,81 & $2.505,15$ & $-2.146,34$ & 14,32 & 121,29 & 112,28 \\
2000 & 308,81 & $2.300,95$ & $-1.992,14$ & 13,42 & 113,54 & 129,55 \\
2001 & 316,76 & $2.437,73$ & $-2.120,97$ & 12,99 & 123,88 & 150,95 \\
2002 & 301,42 & $2.096,15$ & $-1.794,73$ & 14,38 & 110,95 & 134,37 \\
2003 & 328,35 & $2.033,92$ & $-1.705,57$ & 16,14 & 129,82 & 131,91 \\
2004 & 400,07 & $2.409,83$ & $-2.009,76$ & 16,60 & 164,37 & 145,42 \\
2005 & 516,42 & $2.725,60$ & $-2.209,18$ & 18,95 & 192,25 & 146,24 \\
2006 & 677,90 & $3.339,52$ & $-2.661,62$ & 20,30 & 217,68 & 162,21 \\
2007 & 822,80 & $4.410,92$ & $-3.588,12$ & 18,65 & 248,89 & 186,52 \\
2008 & $1.059,87$ & $5.553,80$ & $-4.493,93$ & 19,08 & 279,12 & 208,32 \\
2009 & $1.183,30$ & $5.594,45$ & $-4.411,15$ & 21,15 & 318,55 & 207,96 \\
2010 & $1.363,31$ & $7.534,38$ & $-6.171,07$ & 18,09 & 385,96 & 266,55 \\
2011 & $1.573,50$ & $7.956,50$ & $-6.383,00$ & 19,78 & 443,60 & 257,05 \\
2012 & $1.600,00$ & $8.401,44$ & $-6.801,44$ & 19,04 & 452,09 & 269,42 \\
2013 & $1.605,18$ & $9.101,17$ & $-7.495,99$ & 17,64 & 514,37 & 294,31 \\
2014 & $1.663,20$ & $8.939,26$ & $-7.276,06$ & 18,61 & 503,09 & 311,44 \\
\hline
\end{tabular}

Nota: o quantum refere-se ao valor das importações (ou exportações) em dólares correntes dividido pelo preço das importações (ou exportações). 


\section{Figura 1}

Evolução mensal das séries (em logaritmo natural).

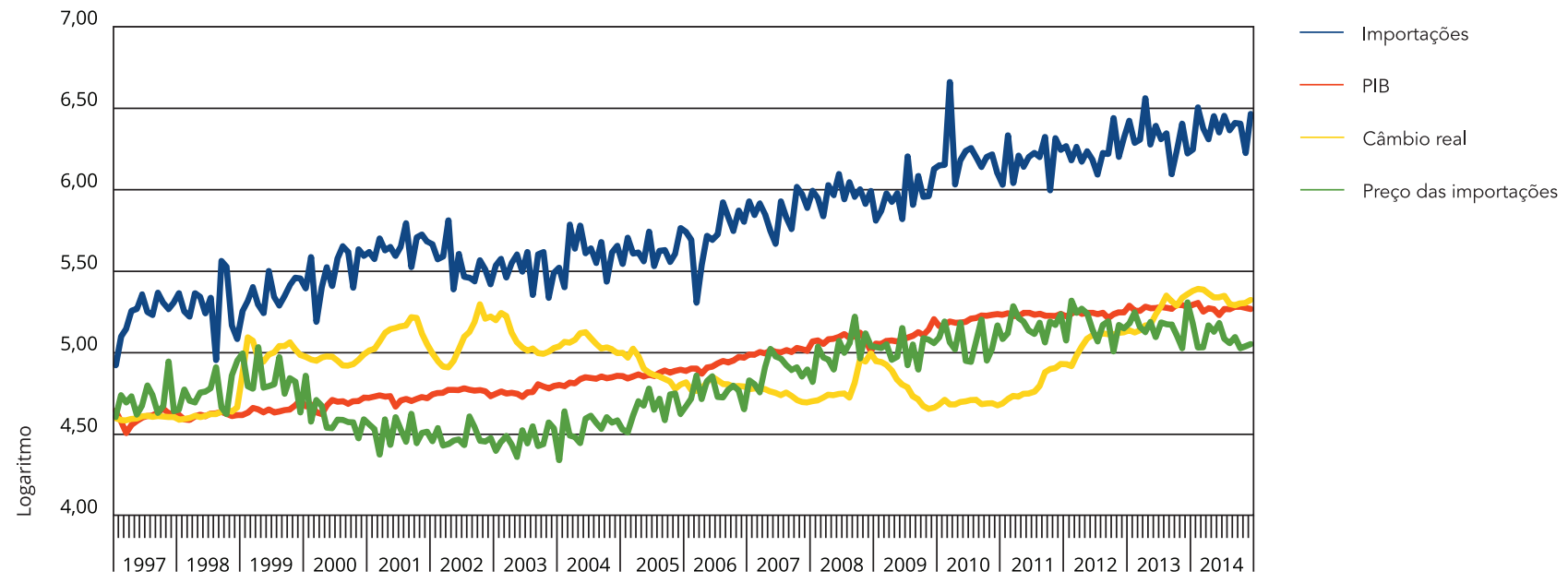

Mês (ano)

Tabela 2

Evolução dos índices dos volumes das importações por segmento. Brasil, 1997-2014.

\begin{tabular}{lcccc}
\hline Ano & Farmacêuticos & Medicamentos & Hemoderivados & Farmoquímicos \\
\hline 1997 & 100,00 & 100,00 & 100,00 & 100,00 \\
1998 & 114,15 & 115,22 & 161,72 & 91,19 \\
1999 & 132,31 & 127,33 & 230,78 & 87,96 \\
2000 & 156,30 & 145,54 & 316,54 & 93,23 \\
2001 & 184,32 & 164,11 & 466,74 & 115,75 \\
2002 & 191,37 & 169,70 & 541,14 & 125,19 \\
2003 & 191,61 & 170,02 & 545,52 & 116,65 \\
2004 & 210,12 & 185,52 & 609,70 & 132,30 \\
2005 & 213,26 & 190,18 & 686,69 & 129,03 \\
2006 & 246,28 & 223,96 & 784,31 & 125,03 \\
2007 & 286,76 & 252,15 & $1.059,16$ & 139,21 \\
2008 & 311,92 & 262,21 & $1.233,79$ & 169,89 \\
2009 & 322,46 & 257,01 & $1.557,63$ & 147,82 \\
2010 & 417,71 & 293,74 & $1.705,94$ & 182,48 \\
2011 & 406,03 & 297,38 & $2.068,61$ & 171,38 \\
2012 & 423,19 & 302,04 & $2.298,31$ & 183,02 \\
2013 & 461,78 & 317,20 & $2.682,01$ & 200,58 \\
2014 & 500,10 & 338,46 & $2.699,48$ & 193,51 \\
\hline
\end{tabular}


Por meio de testes de raiz unitária (não apresentados neste artigo), verificou-se que as séries possuem raiz unitária em nível e são estacionárias nas primeiras diferenças, sendo assim, classificadas como integradas de ordem 1.

A Tabela 3 contém os resultados do teste de cointegração. Como explicado na seção de metodologia, antes da realização desse teste, modelos VAR foram utilizados para obtenção da defasagem ótima com base no critério de Schwarz. Em todos os casos, a hipótese nula de nenhum vetor de cointegração deve ser rejeitada.

Testes de estabilidade do VEC se mostraram satisfatórios. Porém, ocorreu, na maior parte dos casos, violações das hipóteses de normalidade, homocedasticidade e não autocorrelação dos resíduos (resultados não apresentados neste artigo). Modelos com defasagens arbitrárias e inclusão de variáveis binárias para outliers se apresentaram mais satisfatórios, em relação a essas hipóteses dos resíduos (resultados não apresentados neste artigo). Porém, em geral, não sucederam alterações dos resultados e das conclusões, fato que leva a continuar a analisar resultados nas especificações baseadas no critério formal de Schwarz.

As elasticidades estimadas para o preço, renda e da taxa de câmbio em relação às importações são apresentadas na Tabela 4. Pode ser observado que no modelo mais agregado (farmoquímicos e farmacêuticos) todas as variáveis foram estatisticamente significativas em nível de $5 \%$. A elasticidade-renda foi de 1,62 , a do preço $-0,58$ e a da taxa de câmbio $-0,65$.

Em todas as outras estimações, a taxa de câmbio passou a ser estatisticamente não significativa a 5\%. A elasticidade-renda foi significativa em todos os casos, apresentando os valores 2,20; 1,51; 4,56 e 1,34, respectivamente, para os itens farmacêuticos, medicamentos, hemoderivados e farmoquímicos.

A elasticidade-preço das importações não foi significativa para os medicamentos (apesar de ter sido significativa em nível de 10\%) e apresentou os valores de -0,35; -0,47 e -1,17 para os farmoquímicos, farmacêuticos e hemoderivados, sendo as três estatisticamente significativas a $5 \%$.

As velocidades de ajuste de curto para longo prazo foram, respectivamente, $-0,32 ;-0,58 ;-0,68$; -0,82 e -0,69 para farmoquímicos e farmacêuticos, farmacêuticos, medicamentos, hemoderivados e farmoquímicos. Por exemplo, para o caso dos medicamentos, $68 \%$ dos desequilíbrios de curto prazo são corrigidos a cada período.

Tabela 3

Testes de cointegração por segmento das importações.

\begin{tabular}{|c|c|c|c|c|c|}
\hline Segmento & Hipótese & Estatística traço & Valor de $p$ & Autovalor máximo & Valor de $p$ \\
\hline \multirow[t]{3}{*}{ Farmoquímicos e farmacêuticos } & $r=0$ & 77,19 & 0,00 & 35,08 & 0,00 \\
\hline & $r=1$ & 42,11 & 0,00 & 27,52 & 0,00 \\
\hline & $r=2$ & 14,58 & 0,06 & 14,17 & 0,05 \\
\hline \multirow[t]{3}{*}{ Farmacêuticos } & $r=0$ & 85,08 & 0,00 & 40,60 & 0,00 \\
\hline & $r=1$ & 44,48 & 0,00 & 29,05 & 0,00 \\
\hline & $r=2$ & 15,43 & 0,05 & 15,02 & 0,04 \\
\hline \multirow[t]{3}{*}{ Medicamentos } & $r=0$ & 90,67 & 0,00 & 46,55 & 0,00 \\
\hline & $r=1$ & 44,22 & 0,00 & 29,72 & 0,00 \\
\hline & $r=2$ & 14,50 & 0,07 & 13,98 & 0,05 \\
\hline \multirow[t]{3}{*}{ Hemoderivados } & $r=0$ & 101,10 & 0,00 & 57,24 & 0,00 \\
\hline & $r=1$ & 43,87 & 0,00 & 28,70 & 0,00 \\
\hline & $r=2$ & 15,17 & 0,06 & 14,26 & 0,04 \\
\hline \multirow[t]{3}{*}{ Farmoquímicos } & $r=0$ & 71,64 & 0,00 & 39,50 & 0,00 \\
\hline & $r=1$ & 32,14 & 0,03 & 25,57 & 0,01 \\
\hline & $r=2$ & 6,56 & 0,63 & 6,13 & 0,60 \\
\hline
\end{tabular}


Tabela 4

Estimativas das elasticidades por segmento das importações.

\begin{tabular}{|c|c|c|c|c|}
\hline Segmento & $\begin{array}{c}\text { Preço das } \\
\text { importações }\end{array}$ & PIB & Taxa de câmbio & $\begin{array}{c}\text { Velocidade de } \\
\text { ajustamento }\end{array}$ \\
\hline $\begin{array}{l}\text { Farmoquímicos e } \\
\text { farmacêuticos }\end{array}$ & $\begin{array}{c}-0,58 * * * \\
(0,18)\end{array}$ & $\begin{array}{c}1,62 * * * \\
(0,15)\end{array}$ & $\begin{array}{c}-0,65 * * * \\
(0,16)\end{array}$ & $\begin{array}{c}-0,32 * * * \\
(0,09)\end{array}$ \\
\hline Farmacêuticos & $\begin{array}{c}-0,47 * * * \\
(0,12)\end{array}$ & $\begin{array}{c}2,20 * * * \\
(0,10)\end{array}$ & $\begin{array}{l}-0,16 \\
(0,10)\end{array}$ & $\begin{array}{c}-0,58 * \star \star \\
(0,12)\end{array}$ \\
\hline Medicamentos & $\begin{array}{l}-0,22 \text { * } \\
(0,12)\end{array}$ & $\begin{array}{c}1,51 * * * \\
(0,11)\end{array}$ & $\begin{array}{l}-0,05 \\
(0,11)\end{array}$ & $\begin{array}{c}-0,68 * * * \\
(0,11)\end{array}$ \\
\hline Hemoderivados & $\begin{array}{c}-1,17 * * * \\
(0,23)\end{array}$ & $\begin{array}{c}4,56 * * * \\
(0,20)\end{array}$ & $\begin{array}{l}-0,09 \\
(0,21)\end{array}$ & $\begin{array}{c}-0,82 * * * \\
(0,12)\end{array}$ \\
\hline Farmoquímicos & $\begin{array}{c}-0,35 * * \\
(0,15)\end{array}$ & $\begin{array}{c}1,34 * * * \\
(0,13)\end{array}$ & $\begin{array}{l}-0,08 \\
(0,10)\end{array}$ & $\begin{array}{c}-0,69 * * * \\
(0,11)\end{array}$ \\
\hline
\end{tabular}

Nota: $*$ ** $\mathrm{e}^{* * *}$ denotam valor de p menor do que 10\%, 5\% e 1\%. De acordo com critério de Schwarz, foram escolhidas 2 defasagens para todos os modelos.

\section{Discussões}

Inicialmente, como forma de apresentar um cenário geral das importações dos produtos farmoquímicos e farmacêuticos, observou-se sua evolução comparativamente às exportações. Verificou-se um crescimento no déficit da balança comercial desses produtos (diferença entre as exportações e importações). Esse resultado tem sido visto na literatura que defende a existência de um déficit de conhecimento e tecnologia no padrão de comércio exterior de produtos dessa indústria 3,11,12.

Além disso, as importações que já possuíam um valor expressivo tiveram crescimento de forma significativa em todos seus itens, resultado que pode ser constatado de maneira ainda mais forte nos hemoderivados.

Mota 3 observa que os hemoderivados possuem forte e crescente peso no déficit na balança comercial da indústria farmacêutica. $\mathrm{O}$ item medicamentos é o segundo com maior peso nesse déficit. Os países desenvolvidos são a origem de boa parte das importações dos farmacêuticos. Já as importações de fármacos são dependentes da União Europeia e dos Estados Unidos, mas também crescentemente da China e da Índia. Por exemplo, em 2010, 72,4\% das importações desses últimos itens tinham como origem países desenvolvidos, $17,6 \%$ a China e 7,6\% a Índia. Cabe destacar que a classificação no presente trabalho difere da seguida em Mota 3. Como explicitado na metodologia, este trabalho segue a CNAE 2.0, em que os valores apresentados aqui dos produtos farmoquímicos diferem significativamente do trabalho supracitado. Todavia, os valores dos demais itens são bastante semelhantes nesses dois trabalhos.

Notou-se em análise gráfica que, especialmente a partir dos anos 2004-2005, houve aumentos na renda agregada e reduções da taxa de câmbio real (valorização cambial), fatores que tendem a estimular as importações.

Observou-se que as séries são integradas de ordem 1. A existência de raiz unitária implicou a necessidade do teste de cointegração entre as variáveis. Os resultados mostraram que existem relações de equilíbrio de longo prazo entre as variáveis. Assim, as estimativas das elasticidades de longo prazo puderam ser obtidas.

Mostrou-se no modelo mais agregado que as relações têm o comportamento como o esperado, em que as importações se associam positivamente ao nível de atividade econômica. Esse resultado caracteriza esses bens como normais, em que um aumento da renda acarreta em aumento na sua demanda. E, ainda, essa relação é elástica, a saber, um aumento no PIB acarreta em aumento mais do que proporcional na demanda por importações. Por exemplo, um aumento de 1\% no PIB (renda) implica um aumento de 1,62\% nas importações dos farmoquímicos e farmacêuticos. 
As importações têm uma relação negativa com os preços dos importados e com a taxa de câmbio real; o primeiro caso indica que aumentos nos preços desestimulam a demanda e o segundo que aumentos na taxa de câmbio real (desvalorizações cambiais) aumentam os preços relativos gerais, tendo assim, um efeito similar ao desse primeiro caso. Ambas as relações são inelásticas, aumentos nessas variáveis acarretam reduções menos do que proporcionais na demanda por importações de tais produtos.

Relações nesse sentido foram encontradas em alguns trabalhos da literatura com importações totais da economia 13,15, diferentemente de outros artigos que, utilizando também importações totais (com metodologia e/ou periodicidade diferentes dos primeiros), encontram elasticidades renda inelásticas e/ou relações elásticas para a taxa de câmbio 14,17,18.

Quando as importações foram analisadas por segmentos mais desagregados, em todos os casos, a taxa de câmbio real passou a não apresentar relação significativa com as importações. Esse resultado não é como o esperado, entretanto, segundo Kawamoto et al. 20 essa variável não apresenta impacto estatisticamente significativo sobre as importações de produtos industrializados ou um resultado significativo, mas com magnitude pequena.

Nesses segmentos mais desagregados, independentemente do caso, as importações se caracterizaram como bens normais e o aumento da atividade econômica está associado de maneira elástica aos indicadores analisados. Há um coeficiente de impacto sobre as importações de magnitude alta nos hemoderivados e uma relação também elástica, mas de menor impacto sobre as importações dos medicamentos.

Esse resultado dos hemoderivados (alta elasticidade) pode estar relacionado ao seu crescimento bastante acentuado. A literatura informa que a legislação no Brasil proíbe a comercialização de sangues e seus derivados, dessa forma, desde 2001, o Ministério da Saúde adotou a postura de estímulo ao aproveitamento de plasma pela contratação de empresas de outros países para executar serviços relacionados ao fracionamento do plasma 1.

No caso dos preços das importações, eles se apresentam negativamente relacionados às importações dos farmoquímicos, farmacêuticos e dos hemoderivados, sendo uma relação inelástica para os dois primeiros casos e elástica para o último. Portanto, aumentos nos preços geram reduções menos do que proporcionais nas importações dos farmoquímicos e dos farmacêuticos e mais do que proporcionais para os hemoderivados. Os preços das importações não apresentaram impacto significativo (a 5\%) sobre os medicamentos (apesar de haver significância a 10\%). Em resumo, há evidências de que aumentos nos preços das importações desestimulam as importações dos produtos farmoquímicos e farmacêuticos.

Consequentemente, o PIB se mostrou uma variável bastante robusta e importante como determinante das importações dos produtos farmoquímicos e farmacêuticos, sejam em sua forma menos ou mais desagregada. Considerando os argumentos explicitados na literatura de que o déficit no comércio internacional dessa indústria se relaciona com déficit em conhecimento e tecnologia, somando aos resultados encontrados aqui, há indícios de que, à medida que o nível de atividade econômica cresce, ocorre maior demanda por esse tipo de produto, e não havendo produção nacional suficiente, ocorrerá necessidade de importações, gerando pressões no déficit comercial desse segmento, fato que ocorre tanto para os IFA quanto para produtos finais como os medicamentos.

A variável preço também foi significativa na maior parte dos casos, contudo sua importância em termos de magnitude foi menor do que a apresentada pelo PIB. Por fim, a relação entre taxa de câmbio e importações não se mostrou robusta.

Mota 3 observa que apesar do crescimento econômico, a partir de 2006, aconteceu um aumento da razão entre déficit comercial desse setor e PIB, representando maior dependência do país. Esse autor destaca que o desafio não se refere à superação do déficit comercial, mas sim de uma redução da dependência do país, que seria traduzida em um menor déficit de conhecimento e tecnologia.

Nesse caso, as políticas públicas possuem fundamental importância. Algumas iniciativas já implementadas devem ser destacadas, tais como: Projeto Setorial Integrado de Farmoquímicos e Farmacêuticos, BNDES Profarma, Mais Saúde e o Programa de Subvenção Econômica à Inovação, políticas que podem ter apresentado resultados positivos sobre a produção local da indústria farmacêutica e/ ou nas exportações ${ }^{3}$. Todavia, ainda existem grandes desafios para fortalecimento dessa indústria, considerando, por exemplo, a taxa baixa de inovação e de investimento em P\&D do Brasil 5 . 
Cabe frisar algumas das limitações deste trabalho. Uma delas se deve ao fato de que, em razão da disponibilidade de dados, este trabalho utilizou os preços dos farmoquímicos e farmacêuticos de forma agregada, mesmo nas análises de importações mais desagregadas. Outro fato é que, apesar da quantidade de observações não ser pequena, a quantidade de anos que são cobertos pela análise não é grande, podendo influenciar as estimativas de elasticidades.

\section{Colaboradores}

A. M. A. Santos participou da concepção do projeto, escrita do artigo, revisão crítica da literatura relevante e revisão do conteúdo intelectual, análise e interpretação dos dados. C. A. O. Tejada e P. A. Jacinto participaram da redação do artigo, análise, interpretação dos dados e revisão.

\section{Agradecimentos}

Este artigo é parte da Tese de Doutorado de A. M. A. Santos. Agradecemos à Capes pela bolsa oferecida no curso de doutorado na Pontifícia Universidade Católica do Rio Grande do Sul.

\section{Referências}

1. Vargas M. Documento setorial: farmacêutica. In: Gadelha C, coordenador. Projeto Perspectivas do Investimento no Brasil. Brasília: Banco Nacional de Dsenvolvimento Econômico e Social; 2009. p. 1-83.

2. Palmeira-Filho P, Pan S. Cadeia farmacêutica no Brasil: avaliação preliminar e perspectivas. BNDES Setorial 2003; 18:3-22.

3. Mota FB. Evolução do comércio exterior da indústria farmacêutica brasileira pós-liberalização comercial: há evidências de especialização regressiva? [Tese de Doutorado]. Rio de Janeiro: Instituto de Economia, Universidade Federal do Rio de Janeiro; 2013.

4. Gadelha CAG, Quental C, Fialho BC. Saúde e inovação: uma abordagem sistêmica das indústrias da saúde. Cad Saúde Pública 2003; 19:4759.

5. Hasenclever L, Fialho B, Klein H, Zaire C. Economia industrial de empresas farmacêuticas. Rio de Janeiro: E-papers; 2010.

6. Gadelha CAG. Biotecnologia em saúde: um estudo da mudança tecnológica na indústria farmacêutica e das perspectivas de seu desenvolvimento no Brasil [Dissertação de Mestrado]. Campinas: Instituto de Economia, Universidade Estadual de Campinas; 1990.

7. Gadelha CAG. Estudo da competitividade de cadeias integradas no Brasil: impactos das zonas livres de comércio (Cadeia: Complexo da Saúde). Campinas: Instituto de Economia, Universidade Estadual de Campinas/Financidadora de Estudos e Projetos; 2002. 
8. Santos EC, Ferreira MA. A indústria farmacêutica e a introdução de medicamentos genéricos no mercado brasileiro. Nexos Econômi$\cos 2012$; 6:95-120.

9. Guennif S, Ramani SV. Explaining divergence in catching-up in pharma between India and Brazil using the NSI framework. Res Policy 2012; 41:430-41.

10. Instituto Brasileiro de Geografia e Estatística. Conta-satélite de saúde: Brasil 2010-2013. Rio de Janeiro: Instituto Brasileiro de Geografia e Estatística; 2015. (Contas Nacionais, 48).

11. Gadelha CAG. Desenvolvimento, complexo industrial da saúde e política industrial. Rev Saúde Pública 2006; 40 n spe:11-23.

12. Mota FB, Cassiolato JE, Gadelha CAG. Articulação da indústria farmacêutica brasileira com o exterior: há evidências de especialização regressiva? Cad Saúde Pública 2012; 28:527-36.

13. Zini AA. Funções de exportação e de importação para o Brasil. Pesquisa e Planejamento Econômico 1988; 18:615-62.

14. Portugal MS. Um modelo de correção de erros para a demanda por importações brasileira. Pesquisa e Planejamento Econômico 1992; 22:501-40.

15. Azevedo AFZ, Portugal MS. Abertura comercial brasileira e instabilidade da demanda por importações. Nova Economia 1998; 8:37-63.

16. Carvalho A, Parente MA. Estimação de equações de demanda de importações por categorias de uso para o Brasil (1978/1996). Brasília: Instituto de Pesquisa Econômica Aplicada; 1999. (Texto para Discussão, 636).

17. Resende MFC. Crescimento econômico, disponibilidade de divisas e importações totais e por categoria de uso no Brasil: um modelo de correção de erros. Brasília: Instituto de Pesquisa Econômica Aplicada; 2000. (Texto para Discussão, 714).
18. Morais IAC, Portugal MS. A markov switching model for the Brazilian demand for imports: analyzing the import substitution process in Brazil. Brazilian Review of Econometrics 2005; 25:173-219.

19. Santos DF, Barros GSAC. Importações brasileiras de leite: impactos micro e macroeconômicos. Economia Aplicada 2006; 10:541-59.

20. Kawamoto CT, Santana BL, Fonseca H. Elasticidade renda e elasticidade preço das exportações e das importações de produtos industrializados no Brasil (2003-2010): uma avaliação utilizando dados em painel. Revista de Economia 2013; 39:139-59.

21. Poerschke RP, Morais IAC. Determinantes da demanda brasileira por importação de arroz: uma abordagem não linear. Revista de Economia e Sociologia Rural 2014; 52:177-94.

22. Bueno RDLS. Econometria de séries temporais. 2a Ed. São Paulo: Cengage Learning; 2011.

23. Enders W. Applied econometric series. 4th Ed. New York: John Wiley \& Sons; 2015.

24. Hornok A, Larsson R. The finite sample distribution of the KPSS test. Econom J 2000; 3:108-21.

25. Johansen S. Statistical analysis of cointegration vectors. J Econ Dyn Control 1988; 12:231-54.

26. Johansen S. Estimation and hypothesis testing of cointegration vectors in gaussian vector autoregressive models. Econometrica 1991; 59:1551-80.

27. Johansen S, Juselius K. Maximum likelihood estimation and inference on cointegration: with applications to the demand for money. Oxf Bull Econ Stat 1990; 52:169-210. 


\section{Abstract}

This article analyzes the relationship between the demand for importation of pharmacochemical and pharmaceutical products and economic variables (exchange rate, import prices, and aggregate income) in Brazil, using monthly data from 19972014. The main results showed that increases in aggregate income and price reductions in imports have a positive and significant impact (elastic and inelastic, respectively) on imports. Exchange rate was only significant in the more aggregate model. Thus, aggregate income was a robust variable with strong impact on the importation of pharmacochemical and pharmaceutical products. The arguments in the literature that this industry's international trade deficit is related to a deficit in knowledge and technology and the current study's results provide evidence that as economic activity grows, there is a greater demand for this type of product. Additionally, if domestic production is insufficient, there is a need for imports, which can generate pressure on the trade deficit in the industry and contribute to Brazil's dependence on other countries.

Importation of Products; Pharmaceutical Trade; Pharmaceutical Preparations

\section{Resumen}

Este artículo analiza la relación entre la demanda de importaciones de productos farmoquímicos y farmacéuticos y las variables económicas (tasa de cambio, precio de las importaciones y renta agregada), en Brasil, utilizando datos mensuales del periodo 1997-2014. Los principales resultados mostraron que los aumentos en la renta agregada y las reducciones en los precios de las importaciones tienen un impacto positivo y significativo, respectivamente, de forma elástica e inelástica sobre las importaciones. La tasa de cambio fue significativa sólo en el modelo más agregado. Por tanto, la renta agregada se mostró una variable bastante robusta $y$ con un fuerte impacto sobre las importaciones de los productos farmoquímicos y farmacéuticos. Considerando los argumentos explicitados en la literatura, acerca de que el déficit en el comercio internacional de esa industria se relaciona con el déficit en conocimiento y tecnología, sumado a los resultados hallados en este trabajo, hay indicios de que conforme el nivel de actividad económica crece, se produce una mayor demanda por ese tipo de productos, $y$, sin existir producción nacional suficiente, hay una necesidad de importaciones, lo que puede generar presiones en el déficit comercial de este segmento, representando la dependencia de Brasil de otros países.

Importación de Productos; Comercialización de Medicamentos; Preparaciones Farmacéuticas
Recebido em 25/Mai/2016

Versão final reapresentada em 11/Set/2016

Aprovado em 25/Out/2016 